\title{
Dança na escola no Rio Grande do Sul: percursos históricos e pesquisas \\ acadêmicas
}

\section{Dance in the schools in Rio Grande do Sul: historical pathways and academic research}

\author{
Josiane Franken Corrêa \\ Doutora em Artes Cênicas pela Universidade Federal do Rio Grande do Sul (UFRGS) - josianefranken@gmail.com - \\ http://orcid.org/0000-0003-3983-0215 \\ Vera Lúcia Bertoni dos Santos \\ Doutora em Educação pela Universidade Federal do Rio Grande do Sul (UFRGS) - bertonica@gmail.com - \\ http://orcid.org/0000-0002-0708-0942
}

\section{Resumo}

Objetiva mapear a produção acadêmica sobre Dança na Escola no contexto do Rio Grande do Sul, utilizando-se de metodologia qualitativa a partir de revisão de literatura e pesquisa documental. Parte de uma retomada de aspectos históricos, leis e documentos referentes à Dança na Escola no Brasil, seguida de uma contextualização sobre o tema no território sulrio-grandense, e enfoca o desenvolvimento de pesquisas acerca da temática em relação a fatores que influenciam o surgimento de novas propostas pedagógicas, artísticas e científicas no campo em questão. Discute-se a implantação dos cursos de Graduação em Dança no Estado e a criação de programas de pós-graduação que acolhem investigações sobre o assunto, assim como a criação e manutenção de canais de divulgação de pesquisas desta natureza. Como referências principais da investigação, têm-se o trabalho de autores como Hoffmann (2015) e Valle (2016), dentre outros.

Palavras-chave: Dança. Dança na educação. História da dança. Educação Básica.

\begin{abstract}
Objective to map the academic production about Dance in the Schools in the context of Rio Grande do Sul, using a qualitative methodology based on literature review and documentary research. Is based on a resumption of historical aspects, laws and documents related to Dance in the Schools in Brazil, followed by a contextualization on the subject in the territory of Rio Grande do Sul, and focuses on the development of research on the subject in relation to factors that influence the emergence of new pedagogical, artistic and scientific proposals in the field in question. It discusses the implantation of the courses of Graduation in Dance in the State and the creation of Graduate Programs that welcome investigations on the subject, as well as the creation and maintenance of channels of dissemination of research of this nature. As main references of the investigation, have the work of authors like Hoffmann (2015) and Valle (2016), among others.
\end{abstract}

Keywords: Dance. Dance in education. Dance story. Basic Education.

Recebido em: 13/06/2018

Aceito em: 20/03/2019 


\section{INTRODUÇÃO}

Este texto propõe-se a pontuar aspectos históricos que dizem respeito à Dança na Escola no contexto sul-rio-grandense, mapear as investigações sobre a temática realizadas em programas de pós-graduação strictu sensu e identificar meios de divulgação da produção acadêmica sobre a temática desenvolvidos no Rio Grande do Sul.

Originário de uma pesquisa de Doutorado ${ }^{1}$ centrada no tema da docência em Dança nas escolas públicas estaduais do Estado do Rio Grande do Sul (RS), o texto leva em consideração a ampliação das pesquisas referentes ao tema no Brasil (FALKEMBACH, 2017), ocorrida a partir da década de 1990, momento que antecede a promulgação da Lei de Diretrizes e Bases da Educação Nacional (BRASIL, 1996)² e a criação de diversos cursos de Graduação em Dança no país, enfatizando investigações elaboradas entre 1990 e 2017.

A investigação é de abordagem qualitativa, através de revisão de literatura e pesquisa documental, levando em consideração o recorte do contexto selecionado e a consulta a obras de teóricos do campo da dança, dentre os quais se destacam Carmem Anita Hoffmann (2015), Flávia Pilla do Valle (2016) e Andréa Bittencourt de Souza (2015), dentre outros. Considera, também, trabalhos publicados pelas autoras anteriormente (CORRÊA; NASCIMENTO, 2013; CORRÊA; SANTOS, 2019), situando a pesquisa como um estudo contínuo e evolutivo.

Num primeiro momento, foram rastreadas as pesquisas de Mestrado e de Doutorado disponíveis na Biblioteca Digital Brasileira de Teses e Dissertações ${ }^{3}$ (BDTD), tendo o termo “Dança na Escola" inserido no campo "assunto" como o denominador para a busca. A fim de conferir a existência de outras pesquisas que, por algum motivo, não estão listadas no portal da BDTD, no momento seguinte, realizou-se uma busca do mesmo assunto nos repositórios de teses e dissertações de diferentes instituições de ensino superior do RS. O rastreamento encerrou-se num terceiro momento, com a visita a periódicos acadêmicos da Área de Artes disponíveis em meio virtual, em sites de instituições sul-rio-grandenses, o que propiciou identificar canais de divulgação

\footnotetext{
${ }^{1} \mathrm{O}$ texto é resultado da pesquisa de Tese intitulada "Nós, professoras de Dança: ensaio documental sobre a docência em Dança no Rio Grande do Sul" (2018), desenvolvida por Josiane Franken Corrêa, sob orientação da professora Doutora Vera Lúcia Bertoni dos Santos, junto ao Programa de Pós-Graduação em Artes Cênicas da Universidade Federal do Rio Grande do Sul (PPGAC/UFRGS).

${ }^{2}$ Normativa propulsora de diversas ações com relação à inserção da Arte na Educação Básica brasileira.

${ }^{3}$ Disponível em: <http://bdtd.ibict.br/vufind/>
} 
que incentivam e costumam publicar artigos científicos sobre o tema da Dança na Escola no Rio Grande do Sul.

\section{ENSINO SUPERIOR EM DANÇA NO RIO GRANDE DO SUL E MOVIMENTOS DECORRENTES: UMA BREVE CONTEXTUALIZAÇÃO}

Refletir a respeito da Dança no ambiente escolar implica considerar a formação do profissional habilitado para o seu ensino: o professor Licenciado em Dança. De fato, assim como como ocorre nas demais disciplinas do conhecimento, o ensino da dança no meio educacional formal exige um profissional com uma formação específica de nível superior.

Tal colocação, que para os pesquisadores ligados ao campo de estudo denominado Dança na Escola pode constituir uma obviedade, para o senso comum, inclusive o senso comum escolar, muitas vezes soa como uma novidade. Na realidade das nossas escolas de Educação Básica, a presença de um professor de Dança à frente do componente curricular denominado "Arte" é mesmo uma raridade, e o que se observa, na maior parte das instituições, é a prevalência de professores licenciados em Artes Visuais e, em menor número, os licenciados em Dança, em Música e em Teatro, e ainda alguns remanescentes da extinta formação polivalente em Artes (que pretensamente estariam aptos a lecionar nas quatro frentes). Poucos são os professores licenciados em Dança que atuam nas escolas, cujo trabalho suscita uma série de dúvidas e questionamentos e implica desafios à inserção dos seus conteúdos no currículo escolar, à compreensão dos seus propósitos educacionais e ao pleno desenvolvimento das suas ações pedagógicas.

Conforme apontam Corrêa e Santos (2019), as razões dessa ausência de profissionais licenciados em Dança nas escolas brasileiras, refletida na falta de referências sobre o seu ensino no contexto escolar, justificam-se historicamente em função da emergência tardia dos cursos de formação universitária para professores de Dança. Salienta-se que, o primeiro Curso de Graduação em Dança, na Universidade Federal da Bahia (UFBA), entrou em atividade somente em 1956, de forma que essa iniciativa formativa pioneira se fez isolada no tempo, sendo seguida por outras poucas universidades somente no decorrer da década de 1980.

Na década de 1990, impulsionados pelas demandas da Educação Básica, para adequar-se às exigências da LDB 9.394/1996 (BRASIL, 1996), os Cursos Superiores de Dança no Brasil apresentaram crescimento mais evidente; porém, somente a partir dos anos 2000 essa formação se 
expandiu consideravelmente, principalmente em função da implantação do Programa de Apoio a Planos de Reestruturação e Expansão das Universidades Federais (REUNI) 4 .

No Rio Grande do Sul, o primeiro curso de Licenciatura em Dança inicia as suas atividades em 1998, na Universidade de Cruz Alta (UNICRUZ), na cidade de Cruz Alta (RS), localizada a 360 quilômetros da capital, Porto Alegre. Durante quatro anos (1998 - 2002), a UNICRUZ figura como única Instituição de Ensino Superior a ofertar um Curso nesses moldes no estado. Mas o pioneirismo da iniciativa e a importância do trabalho acadêmico voltado à formação de professores de Dança, não são suficientes para garantir o funcionamento do Curso da UNICRUZ, frente aos desafios de uma política institucional adversa à manutenção de suas atividades.

A tese de doutorado de Hoffmann (2015, p. 138), explica as razões para o encerramento das atividades acadêmicas do Curso de Dança da UNICRUZ:

O primeiro motivo pela interrupção estava associado à política institucional, que previa abertura de novas turmas a partir de um número mínimo de alunos matriculados, o que não ocorreu em 2003 e 2004. O outro motivo estava relacionado à migração e adequação dos alunos, que ingressaram nesse período, em turmas em andamento.

A partir de 2002, outras Universidades sul-rio-grandenses criaram seus cursos de Graduação em Dança, o que contempla uma demanda crescente de profissionais interessados na formação específica de professor de Dança nesse contexto. Atualmente, o Rio Grande do Sul destaca-se no cenário nacional como um dos dois estados brasileiros (ao lado de São Paulo) com maior número de Cursos de Graduação em Dança - ao todo existem sete: um Bacharelado, um Tecnológico e cinco Licenciaturas.

O Curso de Bacharelado é ofertado pela Universidade Federal de Santa Maria (UFSM), em Santa Maria (RS); o Curso Tecnológico, pela Universidade de Caxias do Sul (UCS), em Caxias do Sul (RS); e os Cursos de Licenciatura são oferecidos pela Universidade Luterana do Brasil (ULBRA), em Canoas (RS) ${ }^{5}$, pela Universidade Estadual do Rio Grande do Sul (UERGS), em Montenegro (RS), pela Universidade Federal de Pelotas, em Pelotas (RS), pela Universidade Federal do Rio Grande do Sul

\footnotetext{
${ }^{4}$ A discussão sobre a ampliação dos Cursos Superiores de Dança no Brasil é desenvolvida em Pereira e Souza (2014) e Rocha (2016).

5 Disponível em: http://www.ulbra.br/canoas/graduacao/presencial/danca/licenciatura. Acesso em: 10 ago. 2017. Segundo a base de dados referente à Educação Superior no Brasil, gerenciado pelo Ministério da Educação, este curso está em processo de extinção. Disponível em: http://emec.mec.gov.br/. Acesso em: 17 maio 2018.
} 
(UFRGS), em Porto Alegre (RS), e pela Universidade Federal de Santa Maria (UFSM), em Santa Maria (RS).

Esse aumento exponencial da quantidade de cursos de Graduação em Dança reflete-se na qualificação do debate em torno de questões específicas da Área e no crescente número de pesquisadores que a ela se dedicam, motivando a organização do Encontro Estadual de Graduações em Dança. As metas desse importante evento de natureza artística e científica são:

[...] aproximar as graduações em dança (acadêmicos, egressos, professores e amigos) do Rio Grande do Sul para fortalecer uma identidade de classe; promover atividades de pesquisa acadêmica em dança, colaborando para a qualificação e circulação; divulgar trabalhos artísticos de nível acadêmico; promover discussões de temáticas relevantes na área da dança propondo, se necessário, ações políticas por meio de manifesto, carta aberta etc. (VALLE, 2016, p. 23).

Com um formato itinerante, o Encontro teve sua primeira edição no ano de 2009 , em Canoas (RS), município que sedia também a segunda edição do evento, ocorrida em 2011. A terceira edição do Encontro ocorreu em 2012, na cidade de Pelotas (RS); a quarta edição realizou-se em 2014, em Montenegro (RS); e a quinta edição, ocorreu no ano de 2016, teve sua sede na capital, Porto Alegre. O evento destaca-se também pela produção coletiva de documentos de cunho reivindicatório, elaborados com base em necessidades evidenciadas na ação pedagógica e na prática investigativa dos profissionais do ensino da Dança, e que são endereçados a entidades políticas e a órgãos públicos. Um exemplo significativo dessa ação política da categoria, são as cartas elaboradas a partir do Encontro realizado em agosto de 2011, que solicitam ao Governo Estadual a criação de vagas para professores de dança na Rede Pública do Rio Grande do Sul.

É possível constatar os efeitos dessas cartas no quadro de vagas docentes aberto pelo Edital do Concurso Público para o Magistério Estadual (Edital 01/2011 SEDUC RS), para concorrência ao cargo de professor do componente curricular Ensino de Arte, no qual consta a menção às quatro formações na área: Artes Visuais, Dança, Música e Teatro; numa perspectiva inédita de contemplar as quatro linguagens artísticas. O relato de Flávia Pilla do Valle (2016, p. 24), professora do Curso de Licenciatura em Dança da UFRGS, e uma das organizadoras do Encontro das Graduações, reflete sobre essa importante conquista dos profissionais do ensino da Dança:

\footnotetext{
Na segunda "Carta", redigida ao então Secretário da Educação José Clóvis de Azevedo, alertou-se para a importância da dança ser prevista nas vagas do edital a ser lançado para professores da Rede Estadual do Ensino. E, de fato, quando saiu, houve vagas para essa formação [referindo-se à dança].
} 
A movimentação decorrente das demandas criadas a partir da elaboração dos novos cursos de Graduação em Dança, e do crescente número de profissionais deles egressos, gera uma série de iniciativas que resultaram em oferta de trabalho, mesmo que de maneira ainda tímida. A partir de 1998, se destacam períodos com intensificação dessas ofertas e outros em que elas decaem drasticamente, evidenciando altos e baixos ocasionados pela instabilidade política do Brasil e do Rio Grande do Sul.

Assim, é possível inferir que estes altos e baixos acompanham as iniciativas políticas relacionadas ao campo, ou seja, toda vez que um governo se propõe a criar um concurso com vagas específicas para licenciados em Dança, por exemplo, está expandindo consideravelmente a oferta de trabalho para estes profissionais. Dessa maneira, medidas importantes, como a sanção de uma Lei que torna obrigatório o ensino de Dança nas escolas, a criação de uma Base Nacional Comum Curricular, para orientar os princípios norteadores para o ensino dos diferentes componentes curriculares em todo o território brasileiro, e outros documentos referenciais, bem como a busca permanente por parte da categoria dos professores estaduais pelo diálogo com o governo do estado, têm se mostrado aspectos condicionantes para a configuração do Ensino de Arte no ensino básico no contexto da investigação.

Também, o reconhecimento inicial pela formação em Licenciatura em Dança, assim como a necessidade de trabalho legalizado, responsáveis pela manutenção da profissão no estado, mostram-se como consequências da reunião de profissionais atuantes no campo da Dança, em debates políticos e atuação propositiva perante os órgãos responsáveis, assim como da busca e criação de espaços de trabalho, ações realizadas pelos próprios professores recém-formados (CORRÊA; NASCIMENTO, 2013; CORRÊA; SANTOS, 2019).

Segundo a professora Andréa Bittencourt de Souza (2015, p. 41) “[...] esses recentes cursos de Graduação em Dança - e todos os movimentos acadêmicos que deles decorrem - [...] impulsionaram a abertura de concursos públicos para o licenciado em Dança no Estado do RS". Além da oferta de vagas nos concursos públicos do magistério estadual, acontecem, ainda na década de 2000, importantes iniciativas de Prefeituras Municipais, a exemplo dos municípios de São Leopoldo e Montenegro, entre outros. 
Nessa busca por reconhecimento e abertura de frentes de trabalho, por parte da florescente comunidade de professores licenciados em Dança, salienta-se, a elaboração dos Referenciais Curriculares Estaduais para o Ensino de Dança Lições do Rio Grande (RCE) (RIO GRANDE DO SUL, 2009), documento com objetivo de nortear o ensino de Dança na escola pública estadual a partir da apropriação sul-rio-grandense dos Parâmetros Curriculares Nacionais (PCN) (BRASIL, 1997a, 1997b, 1998). Segundo consta no RCE, trata-se da apropriação contextual dos PCN, considerados “[...] necessariamente amplos e, por essa razão, insuficientes para estabelecer a ponte entre o currículo proposto e aquele que deve ser posto em ação na escola e na sala de aula" (RIO GRANDE DO SUL, 2009, p. 11). Assim como os PCN, os RCE possuem uma das suas partes dedicada ao ensino e aprendizagem da Dança, tendo como temas estruturantes para a prática docente: criação, elementos do movimento, relações em dança, apreciação e contextualização.

Com a série de acontecimentos ocorridos desde a promulgação da LDB (BRASIL, 1996), tendo como principais eventos a elaboração dos Parâmetros Curriculares Nacionais, a criação do Curso de Dança da UNICRUZ, a ampliação do número de Licenciaturas em Dança no Brasil e no RS, a publicação dos RCE e a realização de concursos com vagas para professores licenciados em Dança, é possível verificar uma cadeia de ações, na qual cada novo movimento impulsiona e fortalece o campo de estudo relacionado à Dança na Escola (CORRÊA; SANTOS, 2019). Enfatizam-se as pesquisas de Pós-Graduação que, também em função das implicações históricas mencionadas, ocasionam uma mudança na perspectiva, vislumbrando cada vez mais a Dança como uma possibilidade concreta de prática artística na escola, e como um campo de conhecimento autônomo, mas nem por isso isolado ou destituído de aspectos interdisciplinares, muito antes pelo contrário: um campo que se fortalece e se reinventa constantemente na interação com outros campos do conhecimento.

\section{PESQUISAS ACADÊMICAS SOBRE DANÇA NA ESCOLA NO RIO GRANDE DO SUL}

Ao analisar os Anais do Encontro Estadual de Graduações em Dança do RS, em suas diferentes edições (2009, 2011, 2012, 2014, 2016), é possível encontrar reflexões acerca das práticas de dança no ambiente escolar. De modo geral, observa-se um aumento de trabalhos sobre o tema no evento e um crescimento na participação dos acadêmicos das Licenciaturas em Dança do estado. Na primeira e na segunda edição do evento, prevalecem os trabalhos de profissionais já 
formados: como textos resultantes de trabalho de conclusão de um curso de Educação Física, com reflexões sobre a dança na escola (CHAVES; GARCIA, 2009; ROSA; GARCIA, 2009) e uma pesquisa de pós-graduação em andamento (FRANKEN, 2011). A partir do terceiro encontro, nota-se a participação dos futuros professores, aspecto considerado positivo na constituição da cultura profissional que vem se consolidando no estado. Além das pesquisas de graduação (SOUZA; BOMFIM; GUARAGNA; FRAGA; VALLE, 2014; LESSA; JESUS, 2014; FREITAS; SOUZA, 2016; GRANADO; PÓLVORA; CORRÊA, 2016), há textos de professores universitários e estudantes de pós-graduação (CARVALHO; DIAS, 2016).

Numa busca mais ampla sobre as pesquisas acerca da Dança na Escola em nível nacional, desenvolvida a partir do acesso on-line à Biblioteca Digital Brasileira de Teses e Dissertações, é possível encontrar em torno de setenta trabalhos, realizados em programas de pós-graduação de universidades federais, estaduais e privadas, situadas em diferentes regiões do país.

Considerando o período entre 1990 e 2017, a maior parte das pesquisas realiza-se em cursos de mestrado, localizados na região sudeste do Brasil e aborda o tema sob diferentes enfoques, sendo os dois principais: a dança inserida na escola, como disciplina curricular obrigatória e pertencente à Área de Artes e a dança no contexto escolar desenvolvida em práticas com diferentes objetivos, tais como, realização de projetos em turno inverso (ou contra turno) às atividades de classe, integração nos conteúdos de Educação Física, realização de parcerias entre escolas de ensino formal e instituições (academias, escolas estúdios e conservatórios) de ensino não formal de dança, entre outras possibilidades.

Ao reduzir o foco para o contexto do Rio Grande do Sul, é possível encontrar oito pesquisas de Pós-Graduação Strictu Sensu que abordam o tema, sendo cinco dissertações de Mestrado e três teses de Doutorado.

De modo geral ${ }^{6}$, a análise do conteúdo das investigações elaboradas em nível de mestrado, considera que os dois trabalhos desenvolvidos na década de 1990, quando o estado ainda não contava com Cursos de Licenciatura em Dança, enfocam o ensino de Dança como integrante da disciplina de Educação Física. Ou seja, tanto a dissertação de Márcia Gonzalez Feijó (1996) como a

\footnotetext{
${ }^{6}$ Considerando que não é intenção do estudo gerar uma discussão pormenorizada sobre cada pesquisa acadêmica sobre Dança na Escola realizada no Rio Grande do Sul, indicam-se os títulos das dissertações e teses pesquisadas, referenciadas ao final deste texto e disponíveis na internet.
} 
de Sybelle Regina Carvalho Pereira (1997), ambas desenvolvidas no Programa de Pós-Graduação em Ciência do Movimento Humano da Universidade Federal de Santa Maria (UFSM), compreendem a Dança na Escola como conteúdo e não como uma disciplina autônoma - possibilidade concretizada em alguns contextos, somente depois da promulgação da LDB (BRASIL, 1996) e da publicação dos PCN (1997a, 1997b).

Na década de 2000, tem-se a dissertação de Sueli Salva (2003), desenvolvida no Programa de Pós-Graduação em Educação da Universidade Federal do Rio Grande do Sul (UFRGS), tendo por base uma pesquisa qualitativa e etnográfica acerca das significações relativas à dança em um grupo de estudantes de uma escola pública municipal de Porto Alegre, reunidos para essa prática artística no turno inverso ao das atividades de classe. E a dissertação de Ângela Ferreira da Silva (2007), defendida no Programa de Pós-Graduação em Educação da Pontifícia Universidade Católica do Rio Grande do Sul (PUCRS), tendo como foco os significados construídos a partir da aprendizagem da dança, por alunos de uma escola pública municipal de Porto Alegre, envolvidos num projeto extraclasse. Observa-se que apesar desses dois trabalhos situarem-se no contexto da educação formal, ambos enfocam a Dança como atividade extraclasse, cuja prática tem caráter facultativo.

A abordagem da Dança como disciplina curricular da Educação Básica é contemplada somente a partir da década de 2010. Nesse sentido, são verificados quatro trabalhos sobre o tema desenvolvidos no Rio Grande do Sul: uma dissertação de mestrado e três teses de doutorado. A pesquisa em nível de mestrado, realizada no Programa de Pós-Graduação em Artes Cênicas UFRGS, tem autoria de Josiane Franken Corrêa (2012), uma das autoras deste texto, e investiga o processo de construção dos corpos dançantes na escola de ensino formal, problematizando as relações entre os saberes teóricos e práticos que envolvem a disciplina de Dança no meio escolar.

Duas teses de Doutorado sobre o assunto no contexto sul-rio-grandense foram defendidas no Programa de Pós-Graduação em Educação da UFRGS, realizadas por Andréa Bittencourt de Souza (2015), cuja investigação enfoca a constituição da identidade do professor de Arte/Dança na escola sul-rio-grandense, diante do recente processo de inserção curricular da disciplina e por Maria Fonseca Falkembach (2017, p. 11), a qual ancorada metodologicamente na Etnografia Performativa, na Cartografia e na Genética Teatral, analisa o modo como seis professoras graduadas em dança compõem suas práticas artístico-pedagógicas no sistema formal de ensino de escolas públicas no Rio Grande do Sul. 
A terceira tese de Doutorado é a pesquisa da qual se originam as reflexões deste artigo. Defendida no Programa de Pós-Graduação em Artes Cênicas da Universidade Federal do Rio Grande do Sul, no ano de 2018, mapeia a docência em Dança nas escolas públicas estaduais do Rio Grande do Sul (RS), evidenciando possibilidades, limites e estratégias para o ensino de Dança na Educação Básica. Para tanto, contou com a colaboração de cinco professoras licenciadas em dança, atuantes em escolas públicas estaduais do RS.

A busca empreendida e a breve análise dos trabalhos indicam não haver, no contexto selecionado, um aumento considerável no número de investigações sobre o assunto em questão, embora se verifique uma mudança de foco nas investigações. Tal mudança demonstra, por parte da comunidade acadêmica sul-rio-grandense, a validação do ensino de dança na Educação Básica perpassa a dança como conteúdo da disciplina de Educação Física, a dança como oficina de turno inverso às atividades de classe e a dança como uma das especificidades que compõem a disciplina de Ensino de Arte na instituição escolar, como já comentado. A alteração identificada no percurso das pesquisas sobre o tema no estado é resultado de transformações de ordem social e política do país e do ambiente em que as pesquisas se concretizam.

No momento atual, a educação brasileira vive a recente promulgação da Lei 13.278/2016 (BRASIL, 2016), que inclui as quatro linguagens artísticas (artes visuais, dança, música e teatro) no currículo das escolas e se encontra em período de adaptação por parte das instituições de ensino. A inclusão, já orientada pelos PCN em 1997, agora é tornada obrigatória, situação que terá grandes consequências para o campo da Dança na Escola no país.

Outra situação que influencia de maneira direta a prática a pesquisa em Dança na Escola no país, é a publicação da Base Nacional Comum Curricular $(B N C C)^{7}$, que normatiza a organização e o funcionamento do currículo das instituições escolares ${ }^{8}$.

Além desses aspectos, a divulgação dos trabalhos por meio da publicação de artigos em periódicos científicos de cada área específica também interfere no volume de pesquisas e no modo como a produção acadêmica é organizada. Atualmente grande parte dos programas de pósgraduação no Brasil possui revista própria de divulgação científica, responsabilizando-se por receber, avaliar em sistema de colaboração entre pares e publicar artigos de pesquisadores no

\footnotetext{
${ }^{7}$ Disponível em: http://basenacionalcomum.mec.gov.br/. Ver mais em Macedo (2017) e Melo e Souza (2017).

${ }^{8}$ Ver mais em Corrêa e Santos (2019).
} 
intuito de contribuir com as discussões e participar do avanço do seu campo de conhecimento ao compartilhar os resultados das suas investigações. Com a facilidade de acesso proporcionada pelos portais digitais, é possível o envio de textos armazenados em "computadores de uso pessoal" diretamente aos canais de publicação de diferentes instituições, localizadas em diferentes regiões do país e para periódicos internacionais.

Nesse cenário virtual de produção e disseminação acadêmica, considera-se relevante identificar as universidades, instituições e programas de pós-graduação situados no Rio Grande do Sul, com iniciativas relacionadas à divulgação de pesquisas da área de Artes Cênicas, especialmente os que abarcam trabalhos relacionados ao tema da Dança na Escola.

Conforme a Coordenação de Aperfeiçoamento de Pessoal de Nível Superior (CAPES), os principais periódicos ${ }^{9}$ da área de Artes ligados a instituições sul-rio-grandenses são: a Revista Brasileira de Estudos da Presença (FACED UFRGS); a Revista Educação (Centro de Educação UFSM); a Revista Cena (PPGAC UFRGS); a Revista da FUNDARTE (FUNDARTE); a Revista Movimento (ESEFID UFRGS); a Revista Educação (PPGE PUCRS); a Revista Conexão: comunicação e cultura (CCSO UCS); e a Revista Paralelo 31 (PPGAV UFPel).

Esses periódicos caracterizam-se por apresentarem importantes reflexões originadas de pesquisas sobre e em Artes, com enfoque em múltiplas questões relacionadas às diferentes linguagens artísticas, discutidas sob diversas perspectivas e envolvendo aspectos estéticos, pedagógicos, filosóficos, históricos, antropológicos, dentre outros. Porém, as discussões a respeito da relação entre a arte e o ambiente escolar são encontradas em maior número na Revista da FUNDARTE.

Ao considerar os trabalhos publicados entre o primeiro número da Revista, em 2001, e o seu 34으 número, em 2017, é possível identificar mais de 40 artigos publicados referentes à área da Dança, além de um bom número deles relacionarem a Dança e as questões envolvidas na inserção da arte no currículo escolar.

Ao longo dos seus 16 anos de existência, a Revista da FUNDARTE destaca-se por divulgar trabalhos com foco específico no tema Dança na Escola, e outros que, de diferentes formas, se aproximam das discussões relacionadas a processos de Dança na educação de crianças e jovens, a exemplo das pesquisas de Marques (2001), Bins e Valle (2005), Lopes (2006), Vieira e Lima (2008),

\footnotetext{
${ }^{9}$ Em uma rápida consulta na internet, é possível encontrar os portais eletrônicos das revistas citadas.
} 
Tomazzoni (2008), Icle, Costa e Lopes (2009), Parisoto, Pinto e Lopes (2014), Ulrich, Rhoden e Schoellkopf (2014), Corrêa, Martins e Santos (2017), Moojen, Wolffenbuttel e Narvaz (2017), para citar algumas.

\section{CONSIDERAÇÕES FINAIS}

A julgar pela realidade das universidades sul-rio-grandenses, os dados apresentados nesse texto estão ainda longe de sinalizar uma incidência satisfatória de cursos de Licenciatura em Dança, que possam, mesmo num longo prazo, formar a quantidade necessária de profissionais para legitimar a sua atuação nas instituições de Educação Básica.

A Lei 13.278 (BRASIL, 2016), ao tornar obrigatório o ensino de Artes Visuais, Dança, Música e Teatro no contexto escolar brasileiro, resulta em expectativas positivas por parte dos cursos de formação superior, porém, ao mesmo tempo, gera preocupação em razão do baixo número de profissionais habilitados para assumirem as vagas, no caso de efetiva oferta, para professores com formação específica nas diferentes linguagens artísticas.

No que se refere ao outro aspecto abordado no texto, compreendido a partir dos dados referentes às produções acadêmicas relacionadas à Dança na Escola, cabe destacar que, apesar de constituir-se recentemente como campo, evidencia importantes avanços no sentido da discussão de suas múltiplas questões, propiciando reflexões e diálogos sobre diversas formas de abordagem dos seus conteúdos, favorecendo a ampliação conceitual, epistemológica, metodológica e processual dos seus conhecimentos, desenvolvidos em diversificados contextos e perspectivas.

\section{REFERÊNCIAS}

BINS, Gabriela Nobre; VALLE, Flávia Pilla do. Quem não dança segura criança: uma análise do papel da dança nas construções de identidades. Revista da FUNDARTE, Montenegro, ano 5, n. 10, p. 2734, jul./dez. 2005. Disponível em:

http://seer.fundarte.rs.gov.br/index.php/RevistadaFundarte/issue/viewlssue/22/42. Acesso em: 12 jul. 2019.

BRASIL. [LDB]. Lei $\mathbf{n}^{\circ}$ 9.394, de 20 de dezembro de 1996. Estabelece as diretrizes e bases da educação nacional. Brasília, DF: Presidência da República, 1996. Disponível em: http://www.planalto.gov.br/ccivil_03/leis/I9394.htm. Acesso em: 12 jul. 2019.

BRASIL. Lei $n^{\circ}$ 13.278, de 2 de maio de 2006. Altera o $\S 60$ do art. 26 da Lei $n^{\circ} 9.394$, de 20 de dezembro de 1996, que fixa as diretrizes e bases da educação nacional, referente ao ensino da arte. 
Brasília, DF: Presidência da República, 2016. Disponível em:

http://www.planalto.gov.br/ccivil_03/_Ato2015-2018/2016/Lei/L13278.htm\#ART1. Acesso em: 12 jul. 2019.

BRASIL. Secretaria de Educação Fundamental. Parâmetros curriculares nacionais: introdução aos parâmetros curriculares nacionais. Brasília: MEC/SEF, 1997a. Disponível em:

http://portal.mec.gov.br/seb/arquivos/pdf/livro01.pdf. Acesso em: 12 jul. 2019.

BRASIL. Secretaria de Educação Fundamental. Parâmetros curriculares nacionais: arte. Brasília: MEC/SEF, 1997b. Disponível em: http://portal.mec.gov.br/seb/arquivos/pdf/livro06.pdf. Acesso em: 12 jul. 2019.

BRASIL. Secretaria de Educação Fundamental. Parâmetros curriculares nacionais: arte/terceiro e quarto ciclos do Ensino Fundamental. Brasília: MEC/SEF, 1998. Disponível em:

http://portal.mec.gov.br/seb/arquivos/pdf/arte.pdf. Acesso em: 12 jul. 2019.

CARVALHO, Catia; DIAS, Raquel. A dança como possibilidade de micro-rupturas no silenciamento dos corpos escolares. In: ENCONTRO ESTADUAL DE GRADUAÇÕES EM DANÇA, 5., 2016, Porto Alegre. Anais [...]. Porto Alegre: UFRGS, 2016. p. 290-300. Disponível em:

https://www.lume.ufrgs.br/bitstream/handle/10183/149283/001005675.pdf?sequence=1. Acesso em: 12 jul. 2019.

CHAVES, Telma; GARCIA, Angela. Dança escolar: desafios e possibilidades no contexto da arteeducação. In: ENCONTRO ESTADUAL DE GRADUAÇÕES EM DANÇA, 1., 2009, Canoas. Anais [...]. Canoas: ULBRA, 2009. p. 29-46.

CORRÊA, Josiane Franken; MARTINS, lassanã; SANTOS, Vera Lúcia Bertoni dos. Concepções pedagógicas e o ensino de dança na escola. Revista da FUNDARTE, Montenegro, ano 17, n. 34, p. 31-44, ago./dez. 2017. Disponível em:

http://seer.fundarte.rs.gov.br/index.php/RevistadaFundarte/article/view/456/584. Acesso em: 12 jul. 2019.

CORRÊA, Josiane Franken. Dança na escola e a construção do co(rpo)letivo: respingos sobre um processo educativo que dança (dançante que educa?). 2012. Dissertação (Mestrado em Artes Cênicas) - Instituto de Artes, Universidade Federal do Rio Grande do Sul, Porto Alegre: 2012.

CORRÊA, Josiane Franken. Nós, professoras de Dança: ensaio documental sobre a docência em Dança no Rio Grande do Sul. 2018. Tese (Doutorado em Artes Cênicas) - Programa de PósGraduação em Artes Cênicas. Universidade Federal do Rio Grande do Sul, Porto Alegre, 2018.

CORRÊA, Josiane Franken; NASCIMENTO, Flávia Marchi. Ensino de dança no Rio Grande do Sul: um breve panorama. Conceição/Conception. Campinas, v. 2, n. 2, p. 53-68, jul./dez. 2013. Disponível em: Disponível em: https://periodicos.sbu.unicamp.br/ojs/index.php/conce/article/view/8647702. Acesso em: 12 jul. 2019. 
CORRÊA, Josiane Franken; SANTOS, Vera Lúcia Bertoni. Políticas educacionais e pesquisas acadêmicas sobre Dança na Escola no Brasil: um movimento em rede. Revista Brasileira de Estudos da Presença. Porto Alegre, v. 9, n. 1, e82443, 2019. Disponível em: http://www.scielo.br/scielo.php?script=sci_arttext\&pid=S223726602019000100204\&lng=en\&nrm=iso\&tIng=pt. Acesso em: 12 jul. 2019.

FALKEMBACH, Maria Fonseca. Corpo, disciplina e subjetivação nas práticas de dança: um estudo com professoras da rede pública no sul do Brasil. 2017. Tese (Doutorado em Educação) - Programa de Pós-Graduação em Educação. Universidade Federal do Rio Grande do Sul, Porto Alegre, 2017. Disponível em: https://lume.ufrgs.br/handle/10183/169008. Acesso em: 12 jul. 2019.

FEIJÓ, Marcia Gonzalez. A dança como conteúdo integrante da Educação Física escolar enquanto corporeificação do mundo sensível. 1996. Dissertação (Mestrado em Educação) - Centro de Educação Física e Desporto, Universidade Federal de Santa Maria, Santa Maria, 1996.

FRANKEN, Josiane. Corpo letivo: reflexões sobre o corpo que dança na escola. In: ENCONTRO ESTADUAL DE GRADUAÇÕES EM DANÇA, 2., 2011, Canoas. Anais [...]. Canoas: ULBRA/UFRGS, 2011. p. 124-127.

FREITAS, Juliana; SOUZA, Andréa. A dança como uma prática inclusiva no ambiente escolar. In: ENCONTRO ESTADUAL DE GRADUAÇÕES EM DANÇA, 5., 2016, Porto Alegre. Anais [...]. Porto Alegre: UFRGS, 2016. p. 274-289. Disponível em: https://www.lume.ufrgs.br/bitstream/handle/10183/149283/001005675.pdf?sequence=1. Acesso em: 12 jul. 2019.

GRANADO, Ramon; PÓLVORA, Robson; CORRÊA, Josiane Franken Corrêa. In: ENCONTRO ESTADUAL DE GRADUAÇÕES EM DANÇA, 5., 2016, Porto Alegre. Anais [...]. Porto Alegre: UFRGS, 2016. p. 470471. Disponível em:

https://www.lume.ufrgs.br/bitstream/handle/10183/149283/001005675.pdf?sequence=1. Acesso em: 12 jul. 2019.

HOFFMANN, Carmen Anita. A trajetória do Curso de Dança da UNICRUZ (1998 - 2010). 2015. Tese (Doutorado em História) - Programa de Pós-Graduação em História. Pontifícia Universidade Católica do Rio Grande do Sul, Porto Alegre, 2015. Disponível em:

http://tede2.pucrs.br/tede2/handle/tede/2525. Acesso em: 12 jul. 2019.

ICLE, Gilberto; COSTA, Rossana Perdomini Della; LOPES, Sílvia da Silva. Jogo, ludicidade e presença na Pedagogia do Teatro e da Dança. Revista da FUNDARTE, Montenegro, ano 9, n. 17, p. 36-41, jan./jun., 2009. Disponível em:

http://seer.fundarte.rs.gov.br/index.php/RevistadaFundarte/issue/viewlssue/15/35. Acesso em: 12 jul. 2019. 
INSTITUTO FESTIVAL DE DANÇA DE JOINVILLE; ROCHA, Thereza (Org.). Graduações em dança no Brasil: o que será que será?. Joinville: Nova Letra, 2016. Disponível em: http://www.ifdj.com.br/site/wp-content/uploads/2016/07/IX-Seminarios-de-Danca-Graduacoesem-Danca-no-Brasil_Varios-Autores.pdf. Acesso em: 12 jul. 2019.

LESSA, Helena Thoferhn; JESUS, Thiago Silva de Amorim. Proposta de improvisação em dança na escola a partir do tema transversal meio ambiente. In: ENCONTRO ESTADUAL DE GRADUAÇÕES EM DANÇA, 4., 2014, Montenegro. Anais [...]. Montenegro: UERGS, 2014. p. 120-130.

LOPES, Sílvia da Silva. O ensino da dança na pré-escola: uma discussão metodológica. Revista da FUNDARTE, Montenegro, ano 6, n. 11-12, p. 9-12, jan./dez., 2016. Disponível em: http://seer.fundarte.rs.gov.br/index.php/RevistadaFundarte/issue/viewlssue/39/63. Acesso em: 12 jul. 2019.

MACEDO, Elizabeth. As demandas conservadoras do movimento Escola Sem Partido e a Base Nacional Curricular Comum. Educação e Sociedade, Campinas, v. 38, n. 139, p. 507-524, abr./jun. 2017. Disponível em: http://www.redalyc.org/pdf/873/87351644014.pdf. Acesso em: 12 jul. 2019.

MELO, Adriana Almeida Salles de; SOUSA, Flávio Bezerra de. A agenda do mercado e a educação no Governo Temer. Revista Germinal: marxismo e educação em debate, Salvador, v. 9, n. 1, p. 25-36, ago. 2017. Disponível em:

https://portalseer.ufba.br/index.php/revistagerminal/article/view/21619/14336. Acesso em: 12 jul. 2019.

MARQUES, Isabel A.. Do peso de viver à leveza de criar: função social do ensino de dança hoje. Revista da FUNDARTE, Montenegro, ano 1, v. 1/2, n. 2/3, p. 14-17. Disponível em: http://seer.fundarte.rs.gov.br/index.php/RevistadaFundarte/issue/viewlssue/11/17. Acesso em: 12 jul. 2019.

MOOJEN, Alexandra de Castilhos; WOLFFENBUTTEL, Cristina Rolim; NARVAZ, Martha Giüdice. Corpos e gêneros dançam na escola: possibilidades de subversão na educação. Revista da FUNDARTE, Montenegro, ano 17, n. 34, p. 131-152, ago./dez. 2017. Disponível em: http://seer.fundarte.rs.gov.br/index.php/RevistadaFundarte/article/view/462/591. Acesso em: 12 jul. 2019.

PARISOTO, Bruno; PINTO, Aline Silva; LOPES, Sílvia da Silva. Avali-ação: o professor de dança como avaliador de quê? Revista da FUNDARTE, Montenegro, ano 14, n. 27, p. 33-39, jan./jun. 2014. Disponível em: http://seer.fundarte.rs.gov.br/index.php/RevistadaFundarte/article/view/50/135. Acesso em: 12 jul. 2019.

PEREIRA, Sybelle. Dança na Escola: pressupostos fundamentados na perspectiva sóciohistórica de Vigotsky. 1997. Dissertação (Mestrado em Ciência do Movimento Humano) - Programa de PósGraduação em Ciência do Movimento Humano, Universidade Federal de Santa Maria, Santa Maria, 1997. 
PEREIRA, Marcelo de Andrade; SOUZA, João Batista Lima de. Formação superior em Dança no Brasil: panorama histórico-crítico da constituição de um campo de saber. Inter-Ação, Goiânia, v. 39, n. 1, p. 19-38, jan./abr. 2014. Disponível em:

https://www.revistas.ufg.br/interacao/article/view/26443. Acesso em: 12 jul. 2019.

RIO GRANDE DO SUL. Lições do Rio Grande: linguagens códigos e suas tecnologias, Artes e Educação Física. 2009. (Referencial curricular, v. 2).

ROSA, Cristiane; GARCIA, Angela. Dança no contexto escolar: da educação infantil, ensino fundamental a educação especial. In: ENCONTRO ESTADUAL DE GRADUAÇÕES EM DANÇA, 1., 2009, Canoas. Anais [...]. Canoas: ULBRA, 2009. p. 47-67.

SOUZA, Andréa Bittencourt de. Narrativas sobre o ensino da dança: caminhos tramados e traçados em escolas do Rio Grande do Sul. Tese (Doutorado em Educação) - Programa de Pós-Graduação em Educação. Universidade Federal do Rio Grande do Sul, Porto Alegre, 2015. Disponível em: https://lume.ufrgs.br/handle/10183/131888. Acesso em: 12 jul. 2019.

SOUZA, Luciano; BOMFIM, Caroline; GUARAGNA, Gabriela; FRAGA, Gabrielle; VALLE, Flavia Pilla do. Relatos de experiências do Pibid 2013/2: arte-dança nos anos finais do Ensino Fundamental da Escola Estadual Maurício Sirotsky Sobrinho. In: ENCONTRO ESTADUAL DE GRADUAÇÕES EM DANÇA, 4., 2014, Montenegro. Anais [...]. Montenegro: UERGS, 2014. p. 102-112.

TOMAZZONI, Airton. Na dança da pós-modernidade: perspectivas para começar a compreender o desafio da escola hoje. Revista da FUNDARTE, Montenegro, ano 8, n. 16, p. 13-19, jul./dez. 2008. Disponível em: http://seer.fundarte.rs.gov.br/index.php/RevistadaFundarte/issue/viewlssue/18/38. Acesso em: 12 jul. 2019.

ULRICH, Ana Denise; RHODEN, Sandra; SCHOELLKOPF, Suzana. Dança, Música, Artes Visuais e Teatro: reflexões sobre as práticas pedagógicas em sala de aula e o professor propositor. Revista da FUNDARTE, Montenegro, ano 14, n. 28, p. 92-100, jul./dez. 2014. Disponível em: http://seer.fundarte.rs.gov.br/index.php/RevistadaFundarte/article/view/155. Acesso em: 12 jul. 2019.

VALLE, Flávia Pilla do. Encontros anteriores. In: ENCONTRO ESTADUAL DE GRADUAÇÕES EM DANÇA, 5., 2016, Porto Alegre. Anais [...]. Porto Alegre: UFRGS, 2016. p. 23-26. Disponível em: https://www.lume.ufrgs.br/bitstream/handle/10183/149283/001005675.pdf?sequence=1. Acesso em: 12 jul. 2019.

VIEIRA, Alba Pedreira; LIMA, Maristela Moura Silva. Dança educação: poéticas que se encontram em suas relações com a sociedade. Revista da FUNDARTE, Montenegro, ano 8, n. 16, p. 8-12, jul./dez. 2008. Disponível em:

http://seer.fundarte.rs.gov.br/index.php/RevistadaFundarte/issue/viewlssue/18/38. Acesso em: 12 jul. 2019. 